\title{
PEMBUATAN RESIN PENUKAR ION POLISTIREN SULFONAT
}

\author{
A. Zainudin,* Anni Anggraeni, Titin Sofyatin, \& Husein H Bahti \\ Departemen Kimia-Fmipa, Universitas Padjadjaran \\ *Alamat Korespondensi: ahmadzainuddin@ hotmail.com
}

\begin{abstract}
Abstrak: Resin penukar ion telah digunakan untuk pemisahan campuran senyawa kimia ionik, pada kromatografi pertukaran ion. Resin penukar ion adalah polimer yang berikatan dengan gugus fungsional yang mengandung ion yang dapat dipertukarkan. Tujuan dari penelitian ini adalah membuat resin penukar kation dari polistirena terfosfonasi dengan mereaksikan polistirena dan fosfor oksiklorida. Reaksi dilakukan pada kondisi optimum yang meliputi variasi konsentrasi fosfor oksiklorida, suhu dan waktu optimum. Resin penukar ion yang dihasilkan diidentifikasi dengan spektrum inframerah dan dikarakterisasi dengan menentukan massa jenis, penentuan jumlah gugus fosfat pada resin, dan kapasitas pertukaran ion dari resin pertukaran ion yang dihasilkan. Berdasarkan penelitian didapatkan data untuk kondisi optimum yaitu: untuk suhu reaksi, suhu $80{ }^{\circ} \mathrm{C}$; waktu reaksi, 2 jam; konsentrasi fosfor oksiklorida, 17\% (dengan perbandingan fosfor oksiklorida dalam benzena 9:0 $\mathrm{mL}$ ). Hasil inframerah menunjukkan bahwa molekul resin pertukaran ion dari polistirena terfosfonasi terbentuk dan data percobaan untuk massa jenis resin polistirena terfosfonasi adalah 2,0745 g/mL, kapasitas pertukaran ion $2,57 \mathrm{mek} / \mathrm{g}$, dan persentase gugus fosfat yang terikat pada resin yang dihasilkan adalah sebesar $99,14 \%$.
\end{abstract}

Kata Kunci: Resin penukar ion, Polistiren sulfonat

Abstract: Ion exchangers have been used for separating mixtures of ionic chemical compounds, in ion exchange chromatography. The ion-exchanger resin is a polimer which bonding of functional groups containing a counter ions. The aim of this research was a preparing a polystyrene-based phosphonate exchanger by reacting polystyrene and phosphorus oxychloride. The reaction was accomplished at optimal conditions which were determined by conducting reaction experiments at varying reactant concentrations, reaction temperatures, and reaction times. The product of the reaction was identified by infrared spectroscopy and characterized by determining the density, the percentage of the functional group in, and the capacity of the resulted ion exchanger resin. The resulted experimental data show that the optimal reaction conditions were: reaction temperature, $80{ }^{\circ} \mathrm{C}$; time of reaction, 2 hours; concentrations of phosphorus oxychloride, $17 \%$ (in term of volume ratio of phosphorus oxychloride and benzene 9:0 $\mathrm{mL}$ ). The resulted infrared spectra show that a molecule of polystyrene-based phosphonate exchanger has been formed and the experimental data also show that density of the resulted resin was $2.0745 \mathrm{~g} / \mathrm{mL}$, the ion capacity was $2.57 \mathrm{meq} / \mathrm{g}$, and the percentage of phosphate groups in the produced resin was $99.14 \%$.

Keywords:Ion exchange resin, Sulfonate Polystirene

\section{PENDAHULUAN}

Polimer merupakan molekul besar yang terbentuk dari unit-unit berulang sederhana, berbagai modifikasi polimer telah dilakukan oleh beberapa peneliti untuk digunakan secara komersil. Salah satu contoh dari modifikasi polimer adalah ionomer yaitu memasukkan gugus ionik ke sepanjang tulang punggung suatu polimer namun tidak terjadi ikat silang. Sintesis ionomer merupakan suatu fungsionalisasi polimer, sehingga sifat fisik dan sifat kimia polimer dapat berubah secara drastis ( $\mathrm{Li}$ et al, 2001). Resin penukar ion merupakan fasa diam yang digunakan pada kolom kromatografi ion. Kromatografi ion menawarkan metode pemisahan yang mudah dan terpercaya untuk pemisahan dan penentuan ion-ion organik dan anorganik pada suatu campuran (Haddad \& Jackson, 1994). Kendala pemisahan secara kromatografi pertukaran ion pada kolom terbuka adalah memerlukan resin dalam jumlah banyak dengan harga yang mahal, sehingga banyak para peneliti melakukan penelitian mengenai pembuatan resin penukar ion berbahan dasar polimer, baik polimer organik maupun anorganik. Polimer atau ko-polimer stiren memiliki sifat aliran yang konstan pada suhu dibawah suhu degradasi, dan dapat dilelehkan dengan mudah (Gooch, 2007).

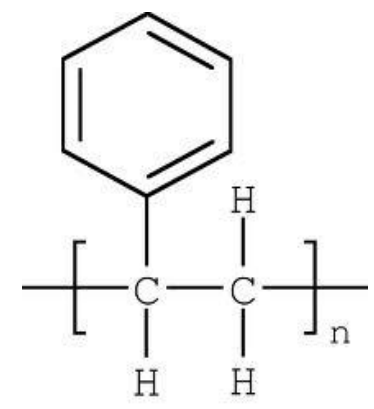

Gambar 1. Struktur Polistirena.

Beberapa peneliti telah melakukan sintesis material pertukaran ion berbahan selulosa, antara lain 
Rucandio (1997) menggunakan resin penukar kation yang sama untuk menentukan 14 unsur tanah jarang dan itrium dalam mineral geologi, Djingova \& Ivanova (2002) menggunakan resin penukar kation DOWEX 50WX8® untuk penentuan unsur tanah jarang dalam tanah dan sedimen, DOWEX merupakan suatu kopolimer polistirena dan divinilbenzen dengan gugus sulfonat. Nada et al. (2002) telah mengolah ampas tebu dan pulp kayu menjadi resin pertukaran kation terfosfonasi dan tersulfonasi yang diaplikasikan untuk pemisahan logam $\mathrm{Fe}, \mathrm{Cr}, \mathrm{Cu}, \mathrm{Pb}, \mathrm{Zn}, \mathrm{Cu}, \mathrm{Cd}$, dan Ni. Dari penelitian tersebut disimpulkan bahwa reaksi fosfonasi menghasilkan resin dengan kapasitas pertukaran ion yang paling besar, karena gugus fosfat yang terikat dalam ampas tebu dan pulp kayu memiliki gugus dianion, sedangkan gugus sulfonat hanya memiliki monoanion yang dapat dipertukarkan.

\section{BAHAN DAN METODE \\ Alat Dan Bahan}

Polistirena, air suling, asam klorida, asam nitrat, asam oksalat, benzena, fosfor oksiklorida, metanol, natrium hidroksida, dan piridin. Peralatan refluks, piknometer, Instrumen Spektrometer Inframerah.

\section{Metode}

\section{Optimasi Reaksi Fosfonasi Polistirena}

Sebanyak 1,0 g polistirena dilarutkan dalam benzena kemudian direndam dalam piridin kering bebas air dalam labu dasar bulat yang dilengkapi dengan pemanas listrik berpengaduk magnet, termometer dan addition funnel. Campuran didinginkan dan diaduk secara kontinyu. Kemudian campuran ditambahkan fosfor oksiklorida dalam benzena dengan perbandingan variasi konsentrasi: $17 \%, 11,3 \%, 8,5 \%, 17 \%, 17 \%$ (dengan perbandingan volume fosfor oksiklorida dalam benzen 9:0; 9:4,5; 9:9; 13:0 dan 15:0 mL), secara tetes demi tetes pada suhu $80 \quad{ }^{\circ} \mathrm{C}$ selama 2 jam. Labu didinginkan, selanjutnya campuran dari dalam labu dituangkan ke dalam air es, lalu disaring. Endapan dicuci berturutturut dengan air suling, asam klorida $0,1 \mathrm{~N}$, air suling sampai netral dan metanol. Endapan dikeringkan di udara terbuka. Nilai kapasitasnya ditentukan dengan cara titrasi asam basa (Nada et al., 2003). Pada waktu reaksi dilakukan dengan cara yang sama, kondisi percobaan dilakukan pada konsentrasi optimum dengan suhu $80{ }^{\circ} \mathrm{C}$ dan variasi waktu reaksi $1 ; 1,5$; 2; 2,5 dan 3 jam. Pada optimasi suhu reaksi dilakukan cara yang sama pada kondisi konsentrasi dan waktu reaksi optimum, dan variasi suhu $70{ }^{\circ} \mathrm{C}, 80{ }^{\circ} \mathrm{C}$ dan $90{ }^{\circ} \mathrm{C}$. Setiap tahap percobaan diamati kapasitas pertukaran ionnya secara titrasi asam basa.

\section{Penentuan Massa Jenis Polistirena Terfosfonasi}

Piknometer dicuci hingga bersih dan dikeringkan lalu ditimbang sampai didapatkan hasil penimbangan yang konstan dalam keadaan kosong
(Wf). Kemudian piknometer tersebut diisi dengan air suling, kemudian ditimbang kembali (Wa), suhu di dalam piknometer yang berisi air suling juga diukur (Tx). Piknometer yang sama dikeringkan kembali kemudian dimasukkan polistiren fosfat, lalu ditimbang (Wo). Piknometer tersebut diisi air suling sampai penuh lalu diukur suhunya (Ts) selanjutnya ditimbang kembali (Wb).

\section{Penentuan Jumlah Gugus Fosfat Dalam Resin Secara Titrasi}

Polistirena sulfonat hasil sintesis dicuci dengan air suling dan disaring, lalu filtrat dititrasi dengan larutan natrium hidroksida $0,05 \mathrm{~N}$.

\section{Kapasitas Pertukaran Ion}

Polistirena terfosfonasi direndam di dalam larutan asam nitrat $1 \mathrm{~N}$, kemudian disaring, dicuci dengan air suling sampai netral dan dikeringkan pada suhu $60{ }^{\circ} \mathrm{C}$ selama 4 jam. Setelah kering, polistirena tersulfonasi ditimbang dengan berat tertentu dan direndam 24 jam dengan $100 \mathrm{~mL}$ larutan natrium hidroksida $0,05 \mathrm{~N}$ yang telah distandardisasi. Setelah itu, campuran disaring dan filtratnya dimasukkan ke dalam buret, lalu dilakukan titrasi terhadap larutan asam oksalat $0,05 \mathrm{~N}$ dengan indikator fenolftalein.

\section{Analisis Spektrum Inframerah}

Analisis dengan spektrofotometer inframerah dilakukan dengan cara menggerus kurang lebih $1 \mathrm{mg}$ polistirena terfosfonasi dengan kalium bromida kering sampai homogen ditekan sampai berbentuk pelet transparan dan dianalisis dengan spektrofotometer inframerah.

\section{HASIL DAN PEMBAHASAN}

Kondisi optimum fosfonasi polistiren diperoleh melalui variasi konsentrasi fosfooksiklorida, waktu reaksi dan suhu reaksi melalui evaluasi kapasitas pertukaran ion. Hasil penelitian ditunjukkan pada Gambar 2, Gambar 3, dan Gambar 4.

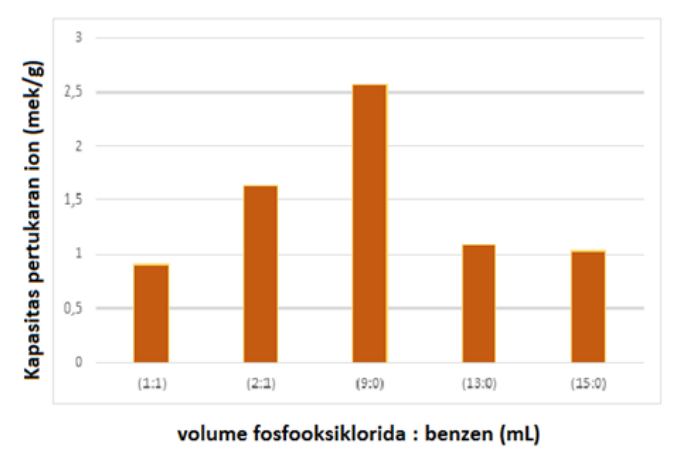

Gambar 2. Pengaruh perbandngan volume fosfooksiklorida : benzena $(\mathrm{mL})$ terhadap kapasitas pertukaran ion 


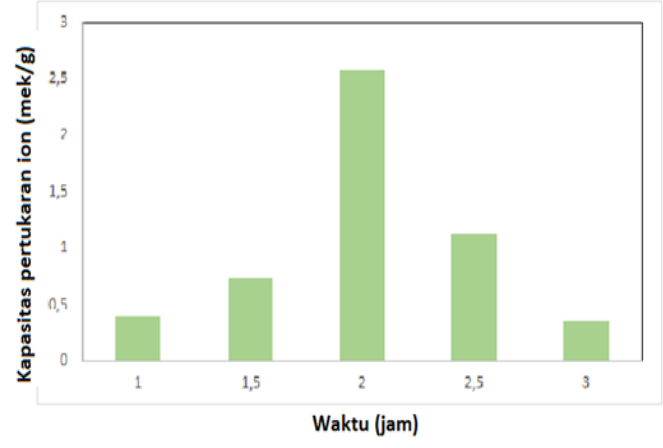

Gambar 3. Pengaruh waktu reaksi fosfonasi terhadap kapasitas pertukaran ion

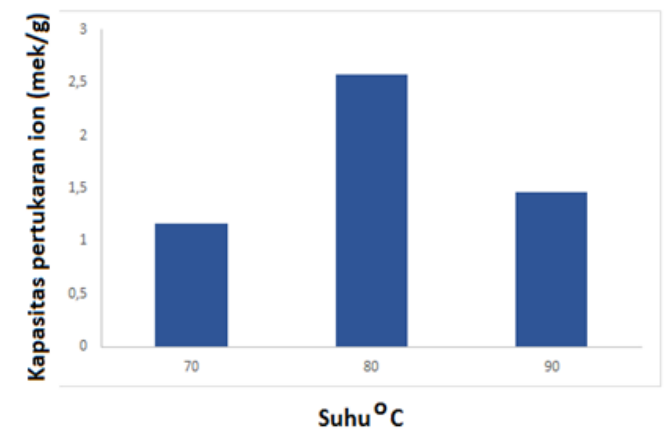

Gambar 4. Pengaruh suhu reaksi fosfonasi terhadap kapasitas pertukaran ion

Kondisi optimum fosfonasi polistiren diperoleh pada konsentrasi fosfooksiklorida $17 \%$, waktu reaksi 2 jam, dan suhu reaksi $80^{\circ} \mathrm{C}$.

Resin penukar ion polistiren fosfonat sebelum dan setelah reaksi fosfonasi dapat dilihat pada Gambar 5.

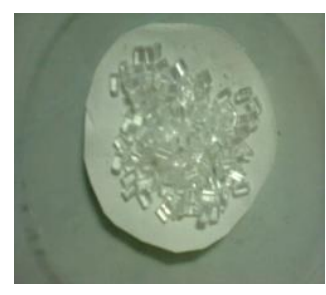

(a)

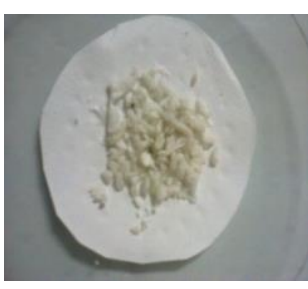

(b)
Gambar 5. (a) Polistiren sebelum reaksi fosfonasi (b) Polistiren setelah reaksi fosfonasi

Kapasitas pertukaran ion adalah kemampuan resin dalam mempertukarkan ion sebanding dengan jumlah gugus aktif yang terikat pada resin. Semakin banyak jumlah gugus yang terikat, maka semakin besar nilai kapasitas pertukaran ion yang dihasilkan. Nilai ini ditentukan dengan titrasi asam basa. Nilai kapasitas pertukaran ion diperoleh dari selisih konsentrasi natrium hidroksida sebelum dan sesudah perendaman resin polistiren fosfonat hasil sintesis.
Pada penelitian ini, kapasitas pertukaran ion untuk resin polistirena terfosfonasi pada kondisi optimum adalah $2,57 \mathrm{mek} / \mathrm{g}$.

Resin polistirena fosfonat memiliki massa jenis rata-rata 2,0745 g/mL, sedangkan polistirena murni mempunyai massa jenis $1,2 \mathrm{~g} / \mathrm{mL}$. Kenaikan nilai massa jenis ini menunjukkan gugus fosfat terikat pada polistirena.

Jumlah gugus fosfat pada resin polistirena terfosfonasi dilakukan dengan cara titrasi asam basa, dengan cara menghitung mmol asam yang tersisa dari hasil reaksi dan mmol asam awal yang digunakan dalam reaksi.

$$
\% \text { fosfat }=\frac{\text { mmol awal asam }- \text { mmol akhir asam }}{\text { mmol awal asam }} \times 100 \%
$$

Pada reaksi fosfonasi, mmol awal fosfor oksiklorida yang digunakan yaitu sebesar 32,7 dan mmol akhir fosfor oksiklorida yang tidak bereaksi dengan polistirena adalah 0,2822. Persentase gugus fosfat dalam resin yang didapat yaitu 99,14\%. Reaksi fosfonasi pada polistiren dapat dilihat pada Gambar 6.<smiles>CCC(C)c1ccc(S(=O)(=O)O)cc1C(=O)OC(Cl)(Cl)C(C)(C)C(CCC(C)(C)C)c1ccccn1</smiles>

Gambar 6. Reaksi fosfor oksiklorida dengan polistiren

Untuk mengetahui adanya gugus fosfat pada resin polistirena fosfonat dilakukan identifikasi dengan spektroskopi inframerah.

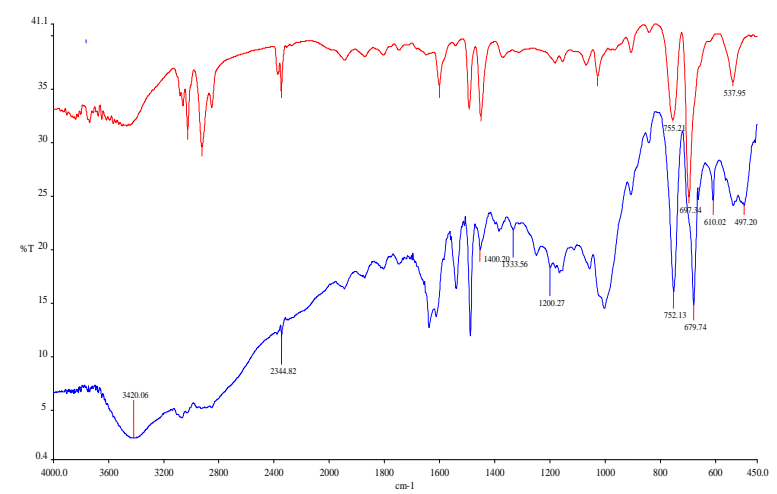

Gambar 6. Karakterisasi spektrum polistirena fosfonat menggunakan spektrofotometer FTIR

Dari hasil analisis spektroskopi inframerah ini terlihat bahwa polistirena memiliki ikatan rangkap dua $\mathrm{C}=\mathrm{C}$ yang ditunjukkan oleh serapan yang khas 
pada panjang gelombang 1490 dan $1600 \mathrm{~cm}^{-1}$. Pada resin terfosfonasi ditemukan puncak baru pada panjang gelombang $1400,2 \mathrm{~cm}^{-1}$ yang merupakan vibrasi dari -P-C, pada $1200 \mathrm{~cm}^{-1}$ sampai $1250 \mathrm{~cm}^{-1}$, yang merupakan regang $\mathrm{P}=\mathrm{O}$. Pada panjang gelombang $3420 \mathrm{~cm}^{-1}$ yang merupakan regang $\mathrm{O}-\mathrm{H}$, dapat terlihat terjadi peningkatan intensitas pada polistirena terfosfonasi. Hal ini disebabkan karena gugus fosfat mengikat dua $-\mathrm{OH}$, sehingga intensitas pun meningkat.

\section{KESIMPULAN}

Dari hasil penelitian dapat disimpulkan bahwa Pembuatan resin penukar kation berhasil dibuat dengan mereaksikan polistirena dengan fosfor oksiklorida $17 \%$, pada suhu $80{ }^{\circ} \mathrm{C}$, waktu reaksi 2 jam. Berat jenis resin yang dihasilkan adalah 2,0745 $\mathrm{g} / \mathrm{mL}$, persentase gugus fosfat di dalam resin adalah $99,14 \%$ dan kapasitas pertukaran ion adalah 2,57 $\mathrm{mek} / \mathrm{g}$.

\section{UCAPAN TERIMAKASIH}

Pada kesempatan ini kami mengucapakan kepada Anggrena Diova Ritonga yang telah membantu penelitian ini, dan kepada Departemen Kimia yang telah memberikan fasilitas pada pelaksanaan penelitian ini.

\section{DAFTAR PUSTAKA}

Djingova, R. \& J. Ivanova. (2002). Determination of rare earth elements in soils and sediments by inductively coupled plasma optical emission spectrometry after cation-exchange separation, Talanta, 5, 821-829.

Gooch, J.W. (2007). Encyclopedic dictionary of polymer, Springer Science and Bussiness Media Ltd., Atlanta.

Haddad, P.R. \& Jackson, P.E. (1994). Ion chromathography: principles and applications, Elsevier, New York.

Li, H., Liu, J., Zhu, F., \& Lin, S. (2001). Synthesis and physical properties of sulfonated polystyrene ionomers, Polymer International, 50, 421-428.

Nada, A.M.A., Eid, M.A., Bahnasawy, R.M. \& Khalifa, M.N. (2002). Preparation and characterization of cation exchangers from agricultural residues, Journal of Applied Polymer Science, 85, 792-800.

Rucandio, M.I. (1997). Cation-exchange isolation ICP-AES determination of rare earth elements in geological silicate materials, Fresenius Journal of Analytical Chemistry, 357, 661-669. 